\title{
Septal myectomy and chordae repair in hypertrophic obstructive cardiomyopathy: A case report
}

\author{
Mohammad Alşalaldeh (D), Bilgin Emrecan (D) \\ Department of Cardiovascular Surgery, Pamukkale University Faculty of Medicine, Denizli, Turkey
}

Received: November 27, 2019 Accepted: June 02, 2020 Published online: November 13, 2020

\section{ABSTRACT}

Hypertrophic obstructive cardiomyopathy is a cardiac disease presenting with the thickened heart muscle and may obstruct left ventricle outflow. A 32-year-old male patient was admitted to our clinic with complaints of weakness, fatigue, and abdominal pain, mostly after meals. He had a systolic anterior motion of the mitral valve concomitantly. He was operated with septal wedge myectomy, resection of the secondary chordae, and plication of the anterior leaflet via the aortic orifice. In conclusion, in such cases the results are satisfactory; however, some patients may later develop mitral regurgitation over time.

Keywords: Chordae repair, hypertrophic obstructive cardiomyopathy, septal myectomy, systolic anterior motion of the mitral valve.

Hypertrophic cardiomyopathy is an inherited disease and occurs in about $1 / 500$ of the population. ${ }^{[1]}$ When left ventricle outflow tract (LVOT) obstruction occurs, the most optimal treatment is surgical septal myectomy. When the gradient at the level of the LVOT obstruction is $\geq 50 \mathrm{mmHg}$ at rest and the patient is considered in the New York Heart Association (NYHA) Class III-IV, surgical septal myectomy is recommended. ${ }^{[2]}$

In this article, we present a case of a hypertrophic septum with the systolic anterior motion (SAM) of the mitral valve successfully treated with aortotomy, wedge resection of the interventricular septum, mitral valve repair.

\section{CASE REPORT}

A 32-year-old male patient presented to our clinic complaining of weakness, fatigue, and abdominal pain, mostly after meals. Investigations were done and the echocardiography showed a mild ( $2^{\text {nd }}$ degree) eccentric mitral valve failure with a SAM of the mitral valve, associated with a thickened septum and diagnosed as a case of hypertrophic obstructive cardiomyopathy (HOCM). The LVOT gradient was $162 / 85 \mathrm{mmHg}$. Mitral valve replacement was recommended to the patient; however, he insistently requested mitral valve repair. A written informed consent was obtained from the patient.
Preparations for the operation were made and the patient underwent an operation where the aortic two-stage venous cannulation was done. After giving a cardioplegic solution in the fashion of antegrade and retrograde, cardiac arrest was achieved and, then, aortotomy was done. Exploration of the septum and mitral valve was done via the aortic orifice. The septum was found to be thickened. Anterior chordae were elongated, leading to SAM of the mitral valve (Figure 1). Septal myectomy was done by resecting a piece of about $8 \mathrm{~mm}$ from the septum, while the anterior leaflet was plicated by 6.0 polypropylene suture through the aortic valve. The suture line was along the clear zone of the mitral anterior leaflet. We resected the secondary chordae that tightened the anterior leaflet. Intraoperative transesophageal echocardiography was used to evaluate valves, SAM of the mitral valve, and LVOT gradient. There were no severe LVOT gradient. The mitral valve was perfectly coaptating and no SAM or mild degree regurgitation was found in the mitral leaflet.

Corresponding author: Mohammad Alşalaldeh, MD. Pamukkale Üniversitesi Tıp Fakültesi Kalp ve Damar Cerrahisi Anabilim Dalı, 20070 Kınıklı, Denizli, Türkiye. Tel: +90 554 - 3349851 e-mail: dr-alshalaldeh@hotmail.com

\section{Citation:}

Alșalaldeh M, Emrecan B. Septal myectomy and chordae repair in hypertrophic obstructive cardiomyopathy: A case report. Cardiovasc Surg Int 2020;7(3):190-192. 


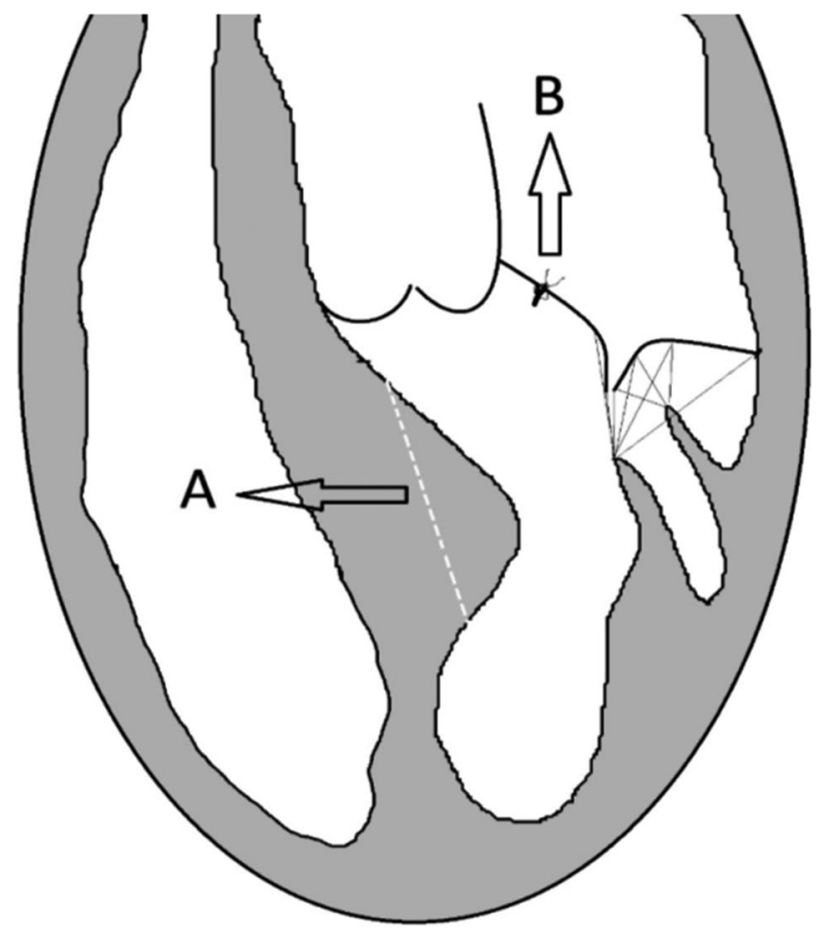

Figure 1. (a) Hypertrophic septum. (b) Anterior mitral leaflet.

Postoperatively, the patient was followed for one day in the intensive care unit and was, then, transferred to the ward. Control echocardiography showed $1^{\text {st }}-2^{\text {nd }}$ degree mitral insufficiency without SAM, and the aortic gradient decreased to $57 / 23 \mathrm{mmHg}$. The patient became free from previous complaints. On postoperative Day 8, the patient was discharged and scheduled for follow-up in the outpatient setting. Unfortunately, after about 18 months of the operation, he was found to have $3^{\text {rd }}$ to $4^{\text {th }}$ degree mitral regurgitation and is symptom-free with medical treatment.

\section{DISCUSSION}

In general, patients with HOCM may develop LVOT obstruction with diastolic dysfunction, myocardial ischemia, and mitral valve regurgitation. These patients usually present with chief complaints of fatigue, palpitation, syncope or presyncope, and chest pain. ${ }^{[3]}$ Similarly, our patient mainly suffered from fatigue and abdominal pain after meals. There is a strong relation between HOCM and SAM: in early systole, the Bernoulli pressure drops, resulting in the anterior leaflet motion of the mitral valve, while the blood flow of the LVOT decelerates and, then, SAM regression occurs in late systole. ${ }^{[4]}$

On other hand, the residual leaflet elongation is found to be more likely in patients with SAM of the mitral valve than non-SAM patients. The long posterior leaflet of the mitral valve is considered a strong risk factor for SAM, while the anterior papillary muscle displacement has been identified as a risk factor, as well. ${ }^{[5]}$ In our case, we found that there were secondary chordae of the mitral valve holding the anterior leaflet tightly and long anterior chordae. We resected the secondary chordae and plicated the long anterior charge after septal myectomy.

After mitral repair for mitral valve regurgitation, there is always a possibility of developing regurgitation again or an increase in the degree of regurgitation. In a study conducted by Flameng et al., ${ }^{[6]}$ even after highly successful repair, the recurrence of mitral valve regurgitation possibility increased over time and occurred at a constant rate, mainly in degenerative valves. ${ }^{[6]}$ In our case, the patient had $3^{\text {rd }}$ to $4^{\text {th }}$ degree mitral regurgitation after about 18 months of surgery, which was $1^{\text {st }}$ to $2^{\text {nd }}$ degree immediately after the operation.

The patient developed mitral regurgitation again after about 18 months. He is still on medication; however, he may need reoperation for valve replacement in the future. In general, repairing the mitral valve apparatus is done through a left atriotomy or, in small left atrium cases, the approach can be achieved via the interatrial septum after right atriotomy. ${ }^{[7]}$ In the cases where aortotomy is done, some prefer performing mitral apparatus repair via aortotomy, particularly when it is associated with septal myectomy. ${ }^{[8]}$ In our case, we preferred performing mitral valve chordae repair via aortotomy and aortic orifice and, the left atrium incision was avoided.

In conclusion, septal wedge myectomy with anterior mitral chordae plication can be done with satisfying results in HOCM associated with SAM cases. However, the possibility of recurrent mitral valve regurgitation over time should be kept in mind.

\section{Declaration of conflicting interests}

The authors declared no conflicts of interest with respect to the authorship and/or publication of this article.

\section{Funding}

The authors received no financial support for the research and/or authorship of this article. 


\section{REFERENCES}

1. Jacoby DL, DePasquale EC, McKenna WJ. Hypertrophic cardiomyopathy: diagnosis, risk stratification and treatment. CMAJ 2013;185:127-34.

2. Ommen SR, Maron BJ, Olivotto I, Maron MS, Cecchi $\mathrm{F}$, Betocchi S, et al. Long-term effects of surgical septal myectomy on survival in patients with obstructive hypertrophic cardiomyopathy. J Am Coll Cardiol 2005;46:470-6.

3. Maron MS, McKenna WJ, Yeon SB. Hypertrophic cardiomyopathy: Clinical manifestations, diagnosis, and evaluation. UpToDate, Waltham, MA 2017. Available at: https://www.uptodate.com/contents/hypertrophiccardiomyopathy-clinical-manifestations-diagnosis-andevaluation [Accessed: April 07, 2016].

4. Lin CS, Chen KS, Lin MC, Fu MC, Tang SM. The relationship between systolic anterior motion of the mitral valve and the left ventricular outflow tract Doppler in hypertrophic cardiomyopathy. Am Heart J 1991;122:1671-82.

5. Manabe S, Kasegawa H, Arai H, Takanashi S. Management of systolic anterior motion of the mitral valve: a mechanism-based approach. Gen Thorac Cardiovasc Surg 2018;66:379-89.

6. Flameng W, Herijgers P, Bogaerts K. Recurrence of mitral valve regurgitation after mitral valve repair in degenerative valve disease. Circulation 2003;107:1609-13.

7. Cohn LH. Mitral valve repair. Oper Tech Thorac Cardiovasc Surg 1998;3:109-25.

8. Dearani JA, Ommen SR, Gersh BJ, Schaff HV, Danielson GK. Surgery insight: Septal myectomy for obstructive hypertrophic cardiomyopathy the Mayo Clinic experience. Nat Rev Cardiol 2007;4:503. 